\title{
Screening for adverse childhood experiences in preventive medicine settings: a scoping review
}

\author{
Kratika Mishra $^{1}$ (D) Daniel E. Atkins ${ }^{1} \cdot$ Brenda Gutierrez $^{1} \cdot$ Jinli Wu ${ }^{2} \cdot$ Michael R. Cousineau $^{3} \cdot$ Susanne Hempel $^{4}$
}

Received: 1 December 2020 / Accepted: 7 April 2021 / Published online: 22 May 2021

(C) The Author(s) 2021

\begin{abstract}
Aim Adverse childhood experiences (ACEs) are associated with numerous adverse mental and physical health outcomes. While interest in routine screening for ACEs is growing, there is still significant opposition to universal screening. This review explores the feasibility of implementing routine screening for ACEs in primary care settings.

Subject and methods We searched PubMed, CINAHL, and PsycINFO, reference-mined relevant reviews, and consulted with key experts (June 2020). Studies from 1970 to date evaluating screening for childhood trauma, adversity, and ACEs in a routine healthcare setting, reporting quantitative or qualitative data were eligible. The project is registered in Open Science Framework (osf.io/5wef8) and reporting follows PRISMA-ScR guidelines.

Results Searches retrieved 1402 citations. Of 246 publications screened as full text, 43 studies met inclusion criteria. Studies evaluated provider burden, familiarity with ACEs, practice characteristics, barriers to screening, frequency of ACE inquiry, reported or desired training, patient comfort, and referrals to support services.

Conclusions This review found that the following factors increase the likelihood that ACE screenings can be successfully integrated into healthcare settings: staff trainings that increase provider confidence and competence in administering screenings, accessible and robust mental health resources, and organizational support. Further research should examine the scalability and sustainability of universal screening.
\end{abstract}

Keywords Adverse childhood experiences $\cdot$ Childhood adversity $\cdot$ Screening $\cdot$ Scoping review

\section{Introduction}

The importance of assessing adverse childhood experiences (ACEs) in clinical practice was first documented in a 1998 study where questions assessing different forms of childhood maltreatment and adversity were implemented as a part of the patient intake (Felitti et al. 1998). The study found that those who had experienced four or more categories of ACEs, compared to those

Kratika Mishra

kratikam@usc.edu

1 Keck School of Medicine, University of Southern California, 1975 Zonal Avenue, Los Angeles, CA 90033, USA

2 Department of Psychology, Georgetown University, Washington, DC, USA

3 Department of Preventive Care and Family Medicine, University of Southern California, Los Angeles, CA, USA

4 The Southern California Evidence-based Practice Center, Los Angeles, CA, USA who had experienced none, had a lifelong increased risk for major health conditions including heart disease, cancer, depression, and chronic lung disease. Furthermore, there was a doseresponse relationship between ACE exposure and health risk; higher ACE exposure was associated with a higher health risk (Felitti et al. 1998). Other research has investigated potential underlying biological mechanisms that may explain this association (Shonkoff and Garner 2012). ACEs affect adults and children from marginalized communities disproportionately and in different clusters (Maguire-Jack et al. 2020; Slopen et al. 2016). As more evidence associating ACEs with poor health outcomes is revealed, ACEs have quickly become recognized as a major public health crisis.

According to the Centers for Disease Control, $61 \%$ of US adults report at least one ACE, and $16 \%$ report four or more different ACEs (CDC 2019). Considering the high prevalence of ACEs and their link to adverse mental and physical health, the utility of ACE screenings as a starting point for trauma-informed care has received significant policy attention (Finkelhor 2018). The American Academy of Pediatrics endorsed incorporating 
screening for ACEs into clinical practice in a 2012 report, citing its usefulness to facilitate trauma informed care and increase education around childhood adversity as a public health crisis (Dube 2018). In addition, Dr. Harris, a pediatrician whose career focus has been on childhood adversity, was appointed California's first surgeon general in 2019 and has spearheaded the implementation of statewide screening of ACEs with the passage of Assembly Bill AB340 (California DHCS 2019). Under the new initiative named ACEs Aware, healthcare providers will be trained and reimbursed to routinely administer ACE screenings to their Medicaid patients (California DHCS 2019). ACE screening would provide a much-needed platform for a dialogue to occur between providers and their patients, and ultimately serve as a step to disrupt the toxic stress response and intergenerational transmission of trauma resulting from ACEs (Waters 2019).

Opposition to routine screening points out that without proper access to evidence-based interventions to employ, once ACEs are identified in adults or children, a universal screening for ACEs would be preemptive (Petruccelli et al. 2019). Furthermore, there is concern that both healthcare providers and patients would be emotionally unequipped to address the possible traumas and negative emotions that may arise from screening (Albaek et al. 2018; Watson 2019). Thus, there exists a need for an analysis of the current evidence on the effects of routine screening for ACEs or any form of childhood adversity in clinical settings. A recent scoping review evaluated the quantitative data and found limited evidence beyond pilot studies for recommendation of routine ACE inquiry (Ford et al. 2019).

This review will assess both the quantitative and qualitative evidence for screening for ACEs or standardized inquiry regarding childhood adversity, in a healthcare setting. The key questions to be answered are:

- KQ1: Can ACE screening be integrated into the routine clinic workflow?

- KQ2: What are provider attitudes regarding ACE screening?

- KQ3: What are patient attitudes regarding screening?

- KQ4: What are the elements of a well-designed and effectively administered screen?

The objective of this review is to provide an index of research that may guide the creation of trauma-informed practices or ACE screening workflows in primary care clinics.

\section{Subject and methods}

\section{Data sources and searches}

This review followed the Arksey and O'Malley (2005) methodological framework for scoping reviews. The search strategy was developed by referring to existing syntheses and known studies (Ford et al. 2019). The search strategy is included in the online appendix, and uses the terms "adverse childhood experiences;" "childhood trauma," "childhood adversity," and "childhood abuse" together with terms for "screening," "enquiry," and "inquiry." The searches were conducted in PubMed for biomedical literature, PsycINFO for psychological literature, and CINAHL for nursing and allied health profession literature. Additional relevant sources were identified through reference mining and interviews with subject experts. Searches were conducted in June 2020.

\section{Study selection}

Using an online tool designed for literature reviews, two reviewers reviewed each title and abstract independently for eligibility toward inclusion in full text screening. The citations that one or both reviewers thought relevant were obtained as full texts. Two reviewers independently screened full-text publications for inclusion applying the explicit eligibility criteria (inter-rater agreement $\mathrm{K}=0.686$ ).

Eligibility criteria were organized in a "SPIOS" framework (study design, participants, Intervention, outcome, setting). Empirical studies reporting on the effects of screening could be eligible, including pilot, cross-sectional, qualitative, and quantitative studies, as well as narrative data reports. Participants could include either providers (encompassing primary care healthcare providers, or other healthcare providers in the context of screening rather than therapy, including but not restricted to, nurses, nurse practitioners, and wellness navigators) or patients (encompassing patients of all ages, caregivers, and prenatal patients). For studies evaluating an intervention, only studies that reports a standardized assessment method within a standard healthcare setting could be eligible. Studies about the process of structured inquiry in any modality for ACEs or childhood trauma that falls into one of the ACE categories (physical, emotional, or sexual abuse; neglect; parental separation, mental illness, or incarceration) (Felitti et al. 1998) could be included. Studies that assess for ongoing childhood maltreatment were excluded. Outcomes regarding structure, process, feasibility, acceptability of provider and patient, provider ACE awareness, beliefs, or practice could be considered eligible. Studies assessing ACEs outside of the normal healthcare system (schools, childcare services) would be excluded. Additionally, research regarding the acceptability of a trauma screen for the purpose of research rather than healthcare delivery would be excluded. Studies were not restricted by geographic location. Forty-three studies met these eligibility criteria for inclusion.

\section{Data abstraction \& critical appraisal}

Data was abstracted in a standardized form in an online software program. Abstraction included study design, location, 
setting, sample size, enquiry tool, objective, and findings for outcomes of interest. The statistical significance of findings was abstracted when available. All included studies were critically appraised for clarity of aim, methods, participants, outcome, analysis, and main findings, as well as estimates of random variability, bias, and transferability to other settings. The appraisal table is included in the online appendix.

\section{Results}

Our searches identified 1402 unique citations, of which 246 were obtained as full-text. Forty-three studies met eligibility criteria. Figure 1 shows the literature flow. Cumulatively, our included studies surveyed a heterogenous group of 5989 individuals, comprised of medical providers, patients, caretakers, trainees, and other healthcare professionals.

The evidence table (Appendix Table 2) provides an overview of all included studies. Studies were conducted in the USA ( $n=29)$, Australia $(n=5)$, Canada $(n=4)$, New Zealand $(n=3)$, and the UK $(n=2)$. Studies were published between 1995 and 2020. Twelve of the included studies were qualitative in nature, and eight used mixed methods. Seven of the identified studies were pilot studies. The most commonly reported topics were: provider attitudes toward ACE screen $(n=$ $22)$, provider-identified barriers to ACE screen $(n=17)$, patient attitudes toward ACE screen $(n=18)$, provider ACE screening rates $(n=18)$, provider referral rates $(n=10)$, and provider preferences regarding further ACE screen training $(n=11)$. Table 1 provides a summary across studies. The results from this scoping review have been qualitatively summarized below and are organized by Key Question.

KQ1: Can ACE screening be integrated into the routine clinic workflow? Three papers reported on workflow variables. One reported that providers at an outpatient pediatric clinic found that the average ACEs conversation lasted 3 to 5 minutes (Gillespie and Folger 2017). Another paper reported that in a family medicine practice, implementing the ACE screen lengthened visits by fewer than 5 minutes for $90 \%$ of encounters. For patients with high ACE scores, $75 \%$ of visits increased by 5 minutes or fewer, and none of the visits were increased by more than $15 \mathrm{~min}$. Only $3 \%$ of patients required 10 to $15 \mathrm{~min}$ of additional visit time (Glowa et al. 2016). The third paper reported that in a primary care practice, the average ACE screen and subsequent discussion lasted $8.5 \mathrm{~min}$, and $80 \%$ lasted $10 \mathrm{~min}$ or less. Patient ACE score and time taken to screen were positively correlated $(p<0.001)$ (Kalmakis et al. 2018).

Gillespie and Folger reported that the most effective question for surveying parents at an outpatient pediatric clinic was "how do you think these experiences affect your parenting today?" (Gillespie and Folger 2017). They also recommend two additional questions when addressing a positive ACE
Fig. 1 PRISMA flow diagram showing study identification, screening, and selection

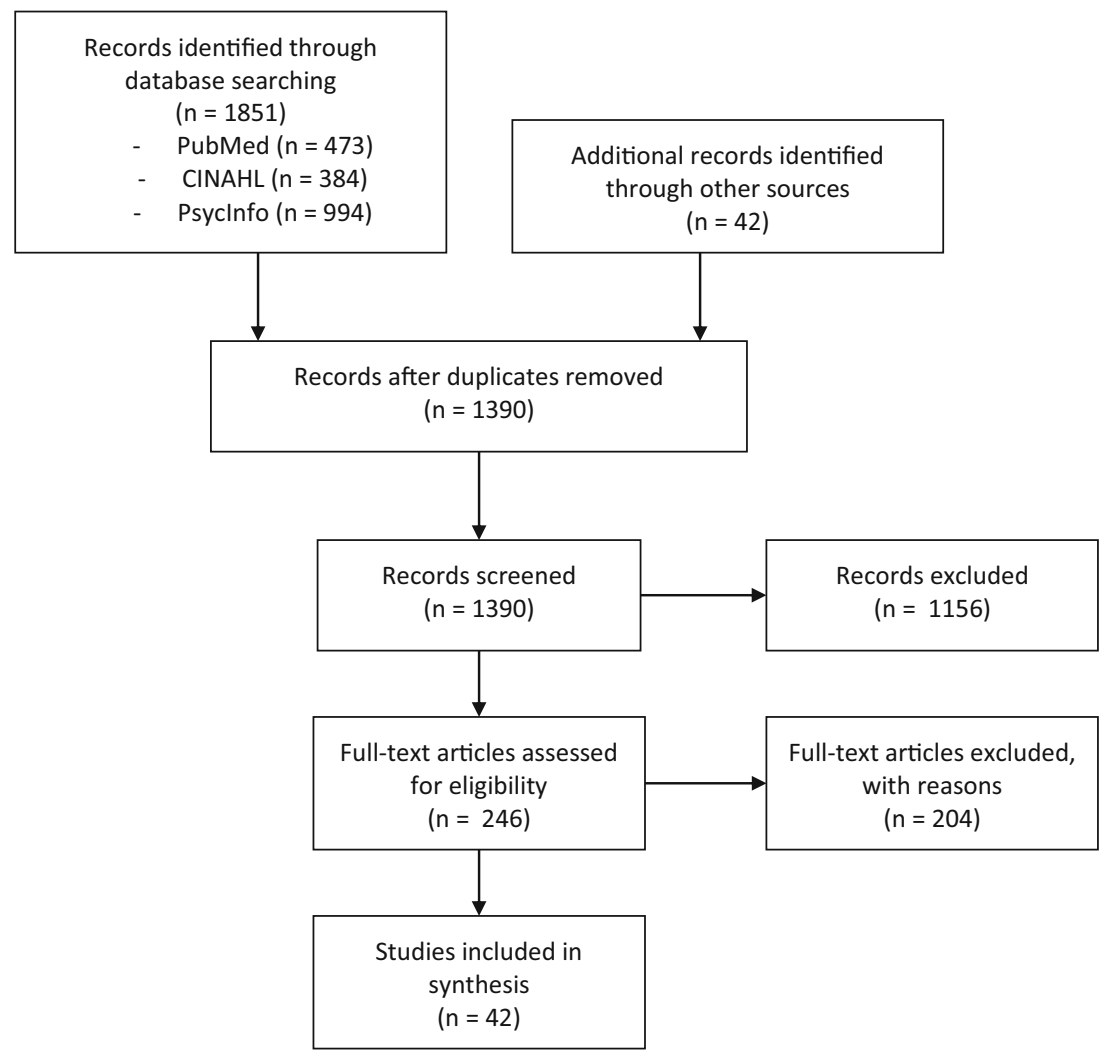


Table 1 Summary of findings

\begin{tabular}{|c|c|c|c|}
\hline Outcome & $\begin{array}{l}\text { Number of } \\
\text { studies } \\
\text { reporting } \\
\text { outcome }\end{array}$ & Major findings & Minor findings \\
\hline $\begin{array}{l}\text { KQ1: } \\
\text { Does ACE } \\
\text { screening disrupt } \\
\text { clinic workflow? } \\
\text { (Provider-identified } \\
\text { barriers to ACE } \\
\text { screening) }\end{array}$ & 17 & $\begin{array}{l}\text { Commonly identified barriers: } \\
\text { - Lack of time to screen and counsel } \\
\text { - Lack of access to resources } \\
\text { - Not provider responsibility } \\
\text { - Overwhelmed with competing care recommendations } \\
\text { - Fear of patient re-traumatization and distress } \\
\text { - Lack of confidence regarding screen }\end{array}$ & $\begin{array}{l}\text { Uncommonly identified barriers: } \\
\text { - Difficulty verifying reports } \\
\text { - Lack of training } \\
\text { - Provider discomfort, second-hand trauma } \\
\text { - Lack of belief in utility of ACE screen } \\
\text { - No reimbursement for screening }\end{array}$ \\
\hline $\begin{array}{l}\text { KQ2: } \\
\text { What are provider } \\
\text { attitudes } \\
\text { regarding ACE } \\
\text { screening? }\end{array}$ & 22 & $\begin{array}{l}\text { In nearly all studies, a majority of providers surveyed } \\
\text { felt that adverse childhood experience (ACE) } \\
\text { screening was a responsibility of their role, was ac- } \\
\text { ceptable to patients, was feasible within an office } \\
\text { visit, and would carry benefit for the patient. Despite } \\
\text { general support for routine screening, providers felt } \\
\text { unprepared to work with trauma patients and } \\
\text { unequipped to deal with trauma disclosures (Green } \\
\text { et al. 2011) }\end{array}$ & $\begin{array}{l}\text { - Screening for ACEs facilitated greater rapport and } \\
\text { trust between provider and patient (Flanagan et al. } \\
2018 \text { ) } \\
\text { - Inquiry about abuse provided context for current } \\
\text { behaviors (Gallop et al. 1995) } \\
\text { - Screening provided an opportunity for further support } \\
\text { (Kalmakis et al. 2017) }\end{array}$ \\
\hline $\begin{array}{l}\text { KQ3: } \\
\text { What are patient } \\
\text { attitudes } \\
\text { regarding } \\
\text { screening? }\end{array}$ & 18 & $\begin{array}{l}\text { A majority of patients surveyed saw value in ACE } \\
\text { screening as part of routine healthcare, and were } \\
\text { willing to discuss their pasts with an experienced } \\
\text { clinician. Patients expressed strong preferences } \\
\text { regarding the administration of the screen; in some } \\
\text { studies, participant support was contingent on certain } \\
\text { factors, including an educated, empathetic approach. } \\
\text { Very few patients opted out of screening or expressed } \\
\text { a resistance to screening. }\end{array}$ & $\begin{array}{l}\text { Some patients reported feeling hopeful or relieved at } \\
\text { trauma inquiry (Lee et al. 2012) Patients expressed } \\
\text { concerns about confidentiality, intrusiveness, } \\
\text { stigmatization, and lack of available interventions } \\
\text { (Robinson et al. 2008) }\end{array}$ \\
\hline \multicolumn{4}{|c|}{ Other outcome measures } \\
\hline $\begin{array}{l}\text { (A) Provider ACE } \\
\text { screening rates }\end{array}$ & 18 & $\begin{array}{l}\text { Providers surveyed included wellness navigators, nurse } \\
\text { practitioners, pediatricians, primary care providers, } \\
\text { psychiatry and family medicine residents, } \\
\text { obstetricians, medical assistants, Licensed clinical } \\
\text { social workers, general practitioners, mental health } \\
\text { practitioners, family physicians. Screening rates } \\
\text { ranged from } 1.8 \% \text { (Tink et al. 2017) to } 92.1 \% \\
\text { (Kia-Keating et al. 2019) }\end{array}$ & $\begin{array}{l}\text { Appendix Table } 3 \text { reports detailed findings regarding } \\
\text { these outcomes, and is included in the online appendix. }\end{array}$ \\
\hline $\begin{array}{l}\text { (B) Provider referral } \\
\text { rates }\end{array}$ & 10 & $\begin{array}{l}\text { Studies reported on frequency of referrals, referral } \\
\text { types, impact of referrals made, and additional } \\
\text { provider responses or treatment options to positive } \\
\text { ACE screen. Providers referred patients to mental } \\
\text { health specialists, prevention services, and insurance, } \\
\text { childcare, and housing resources. }\end{array}$ & \\
\hline $\begin{array}{l}\text { (C) Provider } \\
\text { training } \\
\text { preferences }\end{array}$ & 11 & $\begin{array}{l}\text { Rates of surveyed professionals who had received } \\
\text { formal training about adversity screening ranged } \\
\text { from 44\% (Richardson et al. 2001) to } 94 \% \text { (Lee et al. } \\
\text { 2012). Many participants of qualitative studies } \\
\text { expressed a desire for further education regarding } \\
\text { ACEs, with some emphasizing a wish for in-person } \\
\text { lectures or small group workshops. The rates of sur- } \\
\text { veyed professionals expressing a desire for further } \\
\text { education ranged from 33\% (Young et al. 2001) to } \\
\text { 89\% (Ferrell et al. 2014) in quantitative studies. }\end{array}$ & \\
\hline
\end{tabular}

screen, and especially for follow-up care: "Do any of these experiences bother you now?" and "of those that no longer bother you, how did you get to the point that they don't?" (Gillespie and Folger 2017).
KQ2: What are provider attitudes regarding ACE screening? Twenty-two papers reported on provider attitudes with regard to ACE screening. Gillespie and Folger reported that prior to the implementation of the ACE screen, providers' primary 
concerns were related to deficiencies of time, training, and resources. But once the ACE screening was implemented, many providers found that these factors posed less difficulty than they originally anticipated (Gillespie and Folger 2017). One study reported that physicians were surprised by the prevalence of food, housing, and economic insecurity experienced by their patients' families (Campbell et al. 2020). Two studies reported participant concerns regarding sensitivity toward provider's personal trauma history (Candib et al. 2012; Gallop et al. 1995). Another study reported that providers acknowledged that screening for adversity was personally distressful, but for most respondents, positive emotional experiences outweighed the negative ones and even buffered against burnout (Pearce et al. 2019).

Providers recognized the utility of the ACE screen in multiple identified studies. Campbell et al. reported that although many physicians felt that they were unable to offer useful interventions, they recognized that the screening "planted a seed" for future interactions (Campbell et al. 2020). Other studies reported that nurse practitioners (Kalmakis et al. 2017) and physicians (Kia-Keating et al. 2019) found screening to be a useful tool in forging a clear connection between mental and physical health for patients. In multiple studies, providers including but not limited to primary care providers (Green et al. 2011), nurse practitioners (Branstetter et al. 2020), psychiatry residents (Ferrell et al. 2014), family medicine residents (Tink et al. 2017), pediatricians (Kerker et al. 2016), medical assistants, and wellness navigators (KiaKeating et al. 2019) emphasized the need for further training and education with regard to conducting and responding appropriately to ACE screens.

Green et al. reported that primary care providers described a range of management strategies for working with survivors of trauma: personal strategies (non-judgmental mindset, sensitive language, shared control of discussion with patient), system strategies (routine screening in English or Spanish, part-time mental health professional or family health worker on site), and interventions (resources, on-site Medicaid representatives or social workers, child care, transportation vouchers) (Green et al. 2011).

KQ3: What are patient attitudes regarding screening? Eighteen studies reported on patient attitudes toward screening. Across all studies, a majority of participants found ACE screening to be acceptable. Goldstein et al. reported that nearly all surveyed patients were comfortable being asked about their trauma (directly or through screening) and about discussing their trauma history and its documentation in their medical record, with the expectation that their clinicians knew how to address positive screens (Goldstein et al. 2017). Multiple studies identified factors that contributed to the acceptability of an ACE screen for patients, including the clinician's approachability (Barnett et al. 2020), trust between provider and patient (Conn et al. 2018), confidentiality, and clear statement of purpose (Creedy and Baird 2020). Additionally, a number of studies reported that patients were receptive toward a discussion of their past trauma history and current circumstances, especially if the clinician was attentive, empathetic, experienced, caring, respected their privacy, and connected them with useful resources (Campbell et al. 2020).

Gillespie et al. reported that prenatal women and new parents were open to discussions prompted by ACE screens regarding parenting strategies, to stop the generational transmission of trauma (Gillespie et al. 2017). Two studies reported that patients with higher ACE scores reported lower rates of satisfaction with regard to clinician responses to their ACE screen. (Conn et al. 2018). Both papers identified that patients with higher exposure to ACEs have complex and multifaceted needs, and substantially different experiences within the healthcare system.

Lee et al. provided a summary of qualitative responses to trauma inquiry, which included: shame, embarrassment, discomfort, sadness, hope, relief, gratefulness, and surprise (Lee et al. 2012). A cross-sectional study of pregnant women found that comments regarding negative experiences with the ACE screen alluded to a lack of trust between the provider and patient (Creedy and Baird 2020). Koita et al. surveyed caregivers at a pediatric clinic; many participants expressed discomfort, as the questionnaire triggered painful personal memories, but no caregiver elected to discontinue. Conversely, many caregivers expressed gratitude at the opportunity to discuss family experiences with a trusted provider, and appreciated the targeted support and the need to address these issues to achieve overall health. All participants in this study agreed that screening required some form of follow-up (Koita et al. 2018).

KQ4: What are the elements of a well-designed and effectively administered screen? Four studies reported on provider recommendations regarding screening. One paper reported that nurses in favor of routine inquiry emphasized that the nurse administering the screen must be skilled and the system must have resources in place to respond to client needs (Gallop et al. 1995). In a study of nurse practitioner focus groups, participants noted that direct eye contact with the patient and culturally-sensitive communication with regard to referrals to appropriate resources was paramount (Kalmakis et al. 2017). One study reported that providers recommend clinical supervision, space for providers' emotional processing, and communication of the precise intent of the screen as necessary elements for routine enquiry implementation (Pearce et al. 2019). Mansfield et al. reported that providers identified a need for a whole-system approach, with joint efforts from health providers and community service providers, to adequately and equitably meet the needs of all patients (Mansfield et al. 2017). 
Five studies reported on patient recommendations with regard to screening. Johnson et al. reported that screening most effectively prompts honest responses when conducted by a professional who has existing rapport with the patient, and when the rationale for screening is explained to alleviate potential concerns based on stigmatization (Johnson et al. 2017). One study reported that patients expressed discomfort with ancillary medical staff administering the ACE screen, and expressed the highest level of comfort with primary care providers or mental/behavioral health providers conducting and discussing the ACE screen (Schneider 2020). Gillespie and Folger reported that parents completing screens on behalf of their children were more likely to disclose ACEs in aggregate level reporting than in item-level reporting (i.e., across items rather than based on individual items), indicating that trauma disclosure was more likely if patients did not have to reveal specific details regarding their trauma history (Gillespie and Folger 2017).

White et al. queried focus groups of survivors of abuse for their opinions on trauma inquiry in an obstetric setting. The participants in the White et al. study explained that to optimally frame a "safe" trauma inquiry, providers should provide a definition of trauma, share a clear purpose for the inquiry, provide reassurance that inquiry Is routine (to alleviate stigma), emphasize confidentiality, and offer helpful resources. These women also urged cautiousness around over-emphasis on mental health referral (White and Danis 2016). Muzik et al. gathered qualitative data by surveying trauma-exposed new mothers, who suggested several key elements for a successful trauma-informed health service program: respectful communication, team-based approach to mental health care, broad range of family services, opportunities to strengthen social support networks, and a safe and welcoming environment. The participants in this study also recommended that programs acknowledge their ambivalence toward seeking help while promoting hope-affirming practices in a familycentered setting, because children and motherhood are chief motivators for hope, and a crucial anchor for long-term treatment (Muzik et al. 2013).

\section{Discussion}

Our review of 43 articles revealed strong conceptual support and budding practical evidence for ACE screening. There were more categories of supportive findings for ACE screening than categories of arguments against: Fig. 2 summarizes the evidence. The data regarding implementation of ACE screening show that ACE screening does not excessively disrupt clinic workflow (KQ1), providers report benefits to ACE screening (KQ2), patients report both discomfort and support of a compassionately administered ACE screen (KQ3), and both providers and patients identified the key factors in creating a thoughtfully designed screening process (KQ4). ACE screening is both acceptable on the patient end and feasible on the provider end, as long as the emotional impact of the query is acknowledged and admissions of past adversity are meaningfully addressed. These findings lend support to Felitti's interpretation of his 1998 study's results: the screening for ACEs can itself be a therapeutic intervention that can help reduce traumatic shame that has roots in childhood adversity (Felitti 2019).

To our knowledge, this review is the first to examine both qualitative and quantitative data regarding ACE inquiry in the context of primary healthcare. The inclusion of qualitative research within this review added a critical layer of evidence. Focus groups and interviews of providers and patients allowed more granular information with regard to ACE screening preferences to come to light.

Provider and patient recommendations for integrating ACE screening into healthcare settings frequently echoed the existing principles of trauma-informed care (TIC). A useful theoretical model, described by Machtinger et al. and also supported by other published guidelines, includes four key factors (Purewal et al. 2016):(1) Routine screening for trauma (ongoing, recent, and childhood): Universal inquiry reduces the stigma associated with asking sensitive questions, and facilitates patient education on the link between trauma and health.

(1) Routine screening for trauma (ongoing, recent, and childhood): Universal inquiry reduces the stigma associated with asking sensitive questions, and facilitates patient education on the link between trauma and health.

(2) A systematic response to a disclosure of recent or past trauma: Such a response requires empathetically supporting a patient's disclosure and providing appropriate referrals to resources and services (Machtinger et al.2015).

(3) A clinical environment which promotes healing, and reduces trauma-related triggers (physical and interpersonal aspects) (Machtinger et al. 2015; Oral et al. 2016). Training and education is important to teach healthcare providers, staff, and other personnel about the availability of trauma-specific services and practices (Machtinger et al. 2015). In a model environment, interdisciplinary teams offer well-coordinated care, minimize power differentials between patients and providers, and support providers who may be survivors of trauma or be feeling the effects of vicarious trauma.

(4) Firm institutional commitment to both the values and execution of TIC. Explicitly, the organizational leadership needs to provide support for its staff, work to make connections with other trauma-informed organizations, and regularly evaluate the effectiveness of TIC practices (Machtinger et al. 2015). Healthcare organizations are 
particularly well-equipped to conduct quality assurance and improvement projects that are required to successfully incorporate TIC into a practice (Ko et al. 2008).

It is important to note that every clinical setting has its own unique challenges that increase the difficulty of implementing a trauma-informed approach to healthcare. Although development of a clinical and community infrastructure to support trauma-informed care is the long-term goal, in the short term a thoughtful screening process and a sensitive provider can add value to the patient's healthcare by providing guidance and empathy, or by explaining the toxic effects of childhood adversity.

\section{Limitations \& future directions}

The strengths of this review were its specific eligibility criteria, and systematic search and data abstraction methods. However, this review excluded any research related to ongoing childhood maltreatment or the acceptability of traumafocused research questions (as opposed to trauma-focused healthcare screening). Additionally, there were several limitations of the existing evidence base. Many of the studies were of small sample sizes (12 studies with a sample size less than 25 individuals), and a majority of studies were based in the USA. In the context of the large body of ACE literature that has been published in the last 20 years, and the large number of individuals affected by ACEs, our data, spanning responses from nearly 6000 individuals, pose a limit to the generalizability of our findings. As the prior scoping review on ACE screening noted, the findings were methodologically heterogenous, the studies lacked control groups, and many were observational or pilot studies in similar family-centered settings (Ford et al. 2019).

In light of the increased policy attention to ACEs, further, more robustly designed research is needed to evaluate the ongoing impacts of ACE screening in clinic. Larger epidemiological studies tracking short-term and long-term patient health outcomes and well-being, or healthcare service utilization in patients that undergo routine ACE screening are advisable to further explore the costs and benefits of widespread screening. More research with regard to follow-up care and follow-through on referrals is another potentially key part of evaluating further ACE screening initiatives. Research in different geographic regions, which takes into account the existence and fluctuation of different cultural factors, may also be a valuable expansion of the knowledge base.

Lastly, while primary care is uniquely positioned to incorporate ACEs into well-being, pharmacies, schools, and childcare facilities can also be valuable checkpoints to screen for trauma. Trauma-informed services have utility beyond primary care settings, involving other data-validated tools than the ACE screen.

\section{Conclusion}

The impact of unaddressed ACEs on individual and societal health is not well quantified, but the high prevalence of ACEs
Fig. 2 Diagram of barriers versus supportive factors for ACE screening

\section{Barriers to implementation of routine screening for ACEs}
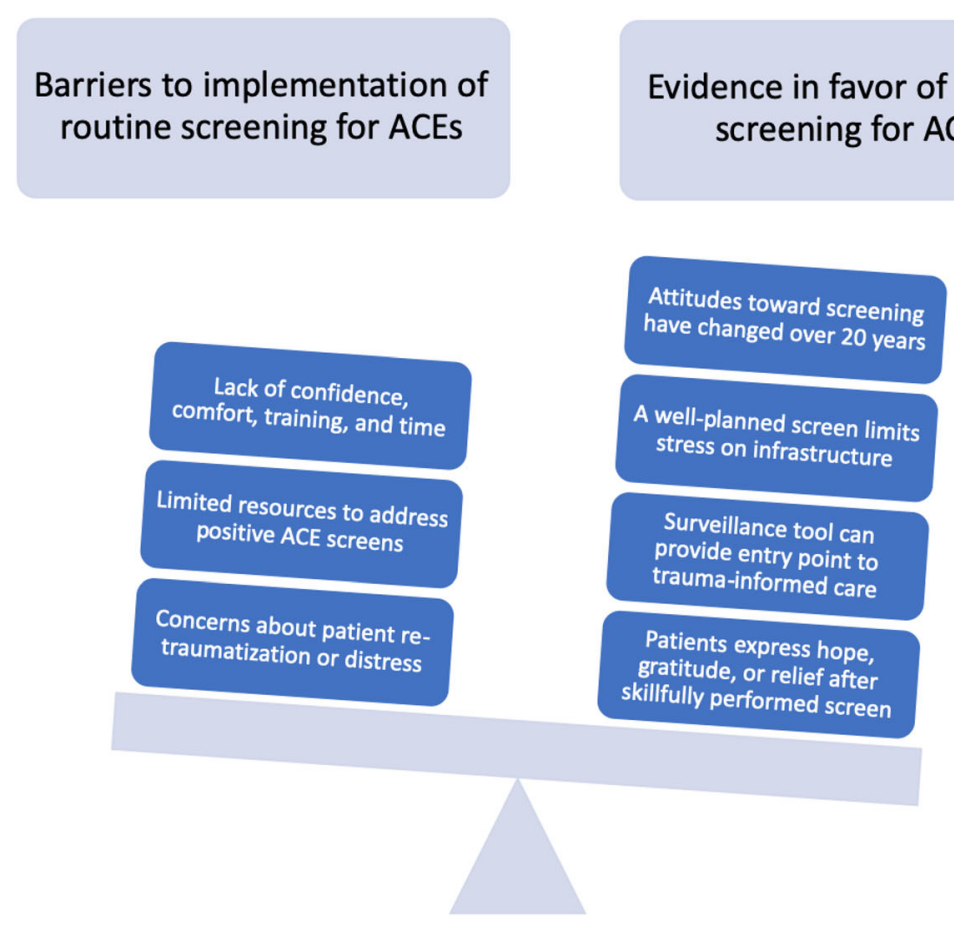

Evidence in favor of routine screening for ACEs 
and the staggering associated morbidity and mortality is potentially one of the biggest challenges facing this generation of medical professionals. In the USA, this threat is more insidious due to the disproportionate effects upon individuals in marginalized communities (Slopen et al. 2016). The medical community has been debating the merits of ACE screening for many years. Opponents of widespread ACE screening often identify the lack of evidence with regard to effective interventions, and potential negative consequences of screening, as the basis for refraining from widespread recommendations (Finkelhor 2018). Although we agree that there is a need for more, targeted research within this topic, our findings emphasize that ACE screening can add value to healthcare by serving as a tool for holistic care. ACE screening can initiate conversations about the link between mental and physical health, aid in the design of parenting strategies for traumaexposed parents, and provide targeted support for patient concerns. A thoughtfully designed approach that integrates community resources, organizational support, and continuous quality improvement efforts that are responsive to patient feedback, is the way toward successful incorporation of routine ACE screening. While routine ACE screening is not the ultimate solution for the large challenge posed by the public health burden of ACEs, we conclude that there is sufficient evidence regarding its feasibility and effectiveness in clinical environments for recommended routine screening to be a meaningful first step.

Supplementary Information The online version contains supplementary material available at https://doi.org/10.1007/s10389-021-01548-4.

Acknowledgements We would like to thank Dr. Jennifer Dinalo for her guidance, and the faculty of the USC Gehr Family Center for Health Systems Science and Innovation for their feedback.

Author contributions $\mathrm{KM}$ conducted the searches, contributed to abstract screening, full-text screening, and conducted the data abstraction and cowrote the paper. DA contributed to abstract screening, full-text screening, co-wrote the paper, completed the formatting, and commented on all stages of the manuscript. BG contributed to the abstract screening and full-text screening, and co-wrote the manuscript. JW led the critical appraisal and commented on multiple stages of the manuscript. MC contributed to development of the project and commented on the manuscript. SH contributed to search strategy development, advised on data synthesis, supervised the project, and commented on all stages of manuscript.

Funding This study was funded by the Gehr Family Center for Health Systems Science and Innovation.

Data availability Not applicable.

Code availability Not applicable.

\section{Declarations}

Ethics approval The authors declare that this review was completed in compliance with ethical standards. The project was reviewed by the
University of Southern California Institutional Review Board and determined to be exempt (ID\#HS-20-00724).”

Consent to participate Not applicable.

Consent for publication Not applicable

Conflicts of interest/competing interests The authors have no relevant financial or non-financial interests to disclose.

Open Access This article is licensed under a Creative Commons Attribution 4.0 International License, which permits use, sharing, adaptation, distribution and reproduction in any medium or format, as long as you give appropriate credit to the original author(s) and the source, provide a link to the Creative Commons licence, and indicate if changes were made. The images or other third party material in this article are included in the article's Creative Commons licence, unless indicated otherwise in a credit line to the material. If material is not included in the article's Creative Commons licence and your intended use is not permitted by statutory regulation or exceeds the permitted use, you will need to obtain permission directly from the copyright holder. To view a copy of this licence, visit http://creativecommons.org/licenses/by/4.0/.

\section{References}

Albaek AU, Kinn LG, Milde AM (2018) Walking children through a minefield: how professionals experience exploring adverse childhood experiences. Qual Health Res 28:231-244. https://doi.org/10. $1177 / 1049732317734828$

Arksey H, O’Malley L (2005) Scoping studies: towards a methodological framework. Int J Soc Res Methodol 8:19-32. https://doi.org/10. 1080/1364557032000119616

Barnett ML, Kia-Keating M, Ruth A, Garcia M (2020) Promoting equity and resilience: Wellness navigators' role in addressing adverse childhood experiences. Clin Pract Ped Psychol 8:176-188. https:// doi.org/10.1037/cpp0000320

Branstetter ML, Garrett-Wright D, Padgett B (2020) Adverse childhood experiences: missed opportunities by nurse practitioners to screen adult clients. J Psychosocial Nursing Mental Health Services 58:20 27. https://doi.org/10.3928/02793695-20191118-01

Campbell KA, Wuthrich A, Norlin C (2020) We have all been working in our own little silos forever: exploring a cross-sector response to child maltreatment. Acad Pedia 20:46-54. https://doi.org/10.1016/j.acap. 2019.06.004

Candib LM, Savageau JA, Weinreb L, Reed G (2012) Inquiring into our past: when the doctor is a survivor of abuse. Fam Med 44:416-424

Conn A-M, Szilagyi MA, Jee SH, Manly JT, Briggs R, Szilagyi PG (2018) Parental perspectives of screening for adverse childhood experiences in pediatric primary care families. Syst Health 36:62-72. https://doi.org/10.1037/fsh0000311

Creedy DK, Baird K, Gillespie K (2020) A cross-sectional survey of pregnant women's perceptions of routine domestic and family violence screening and responses by midwives: testing of three new tools. Women Birth 33:393-400. https://doi.org/10.1016/j.wombi. 2019.06.018

Dube SR (2018) Continuing conversations about adverse childhood experiences (ACEs) screening: a public health perspective. Child Abuse Negl 85:180-184. https://doi.org/10.1016/j.chiabu.2018.03. 007

Felitti VJ (2019) Origins of the ACE study. Am J Prev Med 56:787-789. https://doi.org/10.1016/j.amepre.2019.02.011 
Felitti VJ et al (1998) Relationship of childhood abuse and household dysfunction to many of the leading causes of death in adults: the Adverse Childhood Experiences (ACE) Study. Am J Prevent Med 14:245-258. https://doi.org/10.1016/S0749-3797(98)00017-8

Ferrell NJ, Melton B, Banu S, Coverdale J, Valdez MR (2014) The development and evaluation of a trauma curriculum for psychiatry residents. Academic Psychiatry 38:611-614. https://doi.org/10. 1007/s40596-014-0095-x

Finkelhor D (2018) Screening for adverse childhood experiences (ACEs): cautions and suggestions. Child Abuse Negl 85:174-179. https:// doi.org/10.1016/j.chiabu.2017.07.016

Flanagan T, Alabaster A, McCaw B, Stoller N, Watson C, Young-Wolff KC (2018) Feasibility and acceptability of screening for adverse childhood experiences in prenatal care. J Women's Health 27:903911. https://doi.org/10.1089/jwh.2017.6649

Ford K, Hughes K, Hardcastle K, Di Lemma LCG, Davies AR, Edwards S, Bellis MA (2019) The evidence base for routine enquiry into adverse childhood experiences: A scoping review. Child Abuse Negl 91:131-146. https://doi.org/10.1016/j.chiabu.2019.03.007

Gallop R, McKeever P, Toner B, Lancee W, Lueck M (1995) Inquiring about childhood sexual abuse as part of the nursing history: opinions of abused and nonabused nurses. Arch Psychiatr Nurs 9:146-151. https://doi.org/10.1016/s0883-9417(95)80037-9

Gillespie R, Folger AT (2017) Feasibility of assessing parental ACEs in pediatric primary care: implications for practice-based implementation. J Child Adolesc Trauma 10:249-256

Gillespie SL, Christian LM, Alston AD, Salsberry PJ (2017) Childhood stress and birth timing among African American women: cortisol as biological mediator. Psychoneuroendocrinology 84:32-41. https:// doi.org/10.1016/j.psyneuen.2017.06.009

Glowa PT, Olson AL, Johnson DJ (2016) Screening for adverse childhood experiences in a family medicine setting: a feasibility study. J Am Board Fam Med 29:303-307. https://doi.org/10.3122/jabfm. 2016.03.150310

Goldstein E, Athale N, Sciolla AF, Catz SL (2017) Patient preferences for discussing childhood trauma in primary care. Perm J 21:16-055. https://oi.org/10.7812/tpp/16-055

Green BL et al (2011) Primary care providers' experiences with trauma patients: a qualitative study. Psychol Trauma 3:37

Johnson K et al (2017) Parents' adverse childhood experiences and mental health screening using home visiting programs: a pilot study. Publ Health Nursing 34:522-530. https://doi.org/10.1111/phn.12345

Kalmakis KA, Chandler GE, Roberts SJ, Leung K (2017) Nurse practitioner screening for childhood adversity among adult primary care patients: a mixed-method study. J Am Assoc Nurse Practitioners 29: 35-45. https://doi.org/10.1002/2327-6924.12378

Kalmakis KA, Shafer MB, Chandler GE, Aponte EV, Roberts SJ (2018) Screening for childhood adversity among adult primary care patients. J Am Assoc Nurse Practitioners 30:193-200. https://doi.org/ 10.1097/JXX.0000000000000033

Kerker BD et al (2016) Do pediatricians ask about adverse childhood experiences in pediatric primary care? Acad Pediatr 16:154-160. https://doi.org/10.1016/j.acap.2015.08.002

Kia-Keating M, Barnett ML, Liu SR, Sims GM, Ruth AB (2019) Trauma-responsive care in a pediatric setting: feasibility and acceptability of screening for adverse childhood experiences. Am J Comm Psychol 64:286-297. https://doi.org/10.1002/ajcp.12366

Ko SJ et al (2008) Creating trauma-informed systems: child welfare, education, first responders, health care, juvenile justice. Prof Psychol: Res Pract 39:396-404. https://doi.org/10.1037/07357028.39.4.396

Koita K et al (2018) Development and implementation of a pediatric adverse childhood experiences (ACEs) and other determinants of health questionnaire in the pediatric medical home: A pilot study. PLoS One 13:e0208088. https://doi.org/10.1371/journal.pone. 0208088
Lee A, Coles J, Lee SJ, Kulkarni J (2012) Women survivors of child abuse — don't ask, don't tell. Aust Fam Physician 41:903-906

Machtinger EL, Cuca YP, Khanna N, Rose CD, Kimberg LS (2015) From treatment to healing: the promise of trauma-informed primary care. Womens Health Issues 25:193-197. https://doi.org/10.1016/j. whi.2015.03.008

Maguire-Jack K, Lanier P, Lombardi B (2020) Investigating racial differences in clusters of adverse childhood experiences. Am J Orthopsyc 90:106-114. https://doi.org/10.1037/ort0000405

Mansfield Y, Meehan T, Forward R, Richardson-Clarke F (2017) Asking the question: childhood sexual abuse in adults with mental illness. Australian Soc Work 70:363-371. https://doi.org/10.1080/ 0312407X.2016.1213873

Muzik M, Ads M, Bonham C, Rosenblum KL, Broderick A, Kirk R (2013) Perspectives on trauma-informed care from mothers with a history of childhood maltreatment: a qualitative study. Child Abuse Neglect 37:1215-1224. https://doi.org/10.1016/j.chiabu.2013.07. 014

Oral R et al (2016) Adverse childhood experiences and trauma informed care: the future of health care. Pediatr Res 79:227-233. https://doi. org/10.1038/pr.2015.197

Pearce J, Murray C, Larkin W (2019) Childhood adversity and trauma: experiences of professionals trained to routinely enquire about childhood adversity. Heliyon 5:e01900. https://doi.org/10.1016/j. heliyon.2019.e01900

Petruccelli K, Davis J, Berman T (2019) Adverse childhood experiences and associated health outcomes: a systematic review and meta-analysis. Child Abuse Negl 97:104127. https://doi.org/10.1016/j.chiabu. 2019.104127

CDC (2019) Vital signs: Adverse childhood experiences (ACEs). Centers for Disease Control and Preventioon, Atlanta, GA, USAhttps:// www.cdc.gov/vitalsigns/aces/index.html. Accessed October 22nd, 20202020

Purewal SK, Bucci M, Gutiérrez Wang L, Koita K, Silvério Marques S, Oh D, Burke Harris N (2016) Screening for adverse childhood experiences (ACEs) in an integrated pediatric care model. Zero to Three 37:10-17

Richardson J, Feder G, Eldridge S, Chung WS, Coid J, Moorey S (2001) Women who experience domestic violence and women survivors of childhood sexual abuse: a survey of health professionals' attitudes and clinical practice. Br J Gen Pract 51:468-470

Robinson R et al (2008) Acceptability of adverse childhood experiences questions for health surveillance in U.S. Armed Forces. Military Med 173:853-859. https://doi.org/10.7205/MILMED.173.9.853

Schneider M (2020) What parents want: preferences for mental/ behavioral health screening implementation procedures in pediatric primary care. Ph.D. dissertation, University of South Alabama

California DHCS (2019) Assembly Bill 340 - Trauma Screening Advisory Workgroup. California Department of Health Care Services, Sacramento, CA, USA. https://www.dhcs.ca.gov/Pages/ AB340.aspx. Accessed October 22nd, 20202020

Shonkoff JP, Garner AS (2012) The lifelong effects of early childhood adversity and toxic stress. Pediatrics 129:e232-e246. https://doi.org/ 10.1542/peds.2011-2663

Slopen N, Shonkoff JP, Albert MA, Yoshikawa H, Jacobs A, Stoltz R, Williams DR (2016) Racial disparities in child adversity in the U.S.: interactions with family immigration history and income. Am J Prev Med 50:47-56. https://doi.org/10.1016/j.amepre.2015.06.013

Tink W, Tink JC, Turin TC, Kelly M (2017) Adverse childhood experiences: survey of resident practice, knowledge, attitude. Fam Med 49:7-13

Waters R (2019) California surgeon general puts spotlight on childhood trauma vol 2020. California Health Care Foundation, Oakland, CA, USA. chcf.org 
Watson P (2019) How to screen for ACEs in an efficient, sensitive, and effective manner. Paediatr Child Health 24:37-38. https://doi.org/ $10.1093 / \mathrm{pch} / \mathrm{pxy} 146$

White A, Danis M, Gillece J (2016) Abuse survivor perspectives on trauma inquiry in obstetrical practice. Arch Women's Mental Health 19:423-427. https://doi.org/10.1007/s00737-015-0547-7
Young M, Read J, Barker-Collo S, Harrison R (2001) Evaluating and overcoming barriers to taking abuse histories. Prof Psychol: Res Pract 32:407-414. https://doi.org/10.1037/0735-7028.32.4.407

Publisher's note Springer Nature remains neutral with regard to jurisdictional claims in published maps and institutional affiliations. 